\title{
Geotechnology of restoration of culverts in complex ground conditions without their decommissioning
}

\author{
Nicolay Perminov ${ }^{1, *}$ and Andrey Perminov ${ }^{2}$ \\ ${ }^{1}$ Emperor Alexander I State Transport University, 9 Moskovsky Pr., St. Petersburg, 190031, Russia \\ ${ }^{2}$ NPF Transspetstroy, 24 Furshtatskaya St., St. Petersburg, 191028, Russia
}

\begin{abstract}
In the article, on the basis of extensive theoretical and experimental research carried out, innovative geotechnology for repair of culverts is presented, which provides an improvement in the conditions for interaction between the body of the structure and the soil massif with increasing technogenic impacts. The analysis of the technical condition of the culvert transport and engineering structures under special operating conditions is given. Factors determining their premature emergency condition and interfering with stable functioning under increasing loads and impacts have been studied. On the basis of many years of experimental and theoretical and experimental design work, geotechnology «Saturn» has been proposed, suitable for repairing all types of culverts on railroads and highways, engineering infrastructure facilities, and especially for repair and reconstruction of pipes under conditions of a constant intensive watercourse with nonstandard (atypical) constructive solutions, as well as located in hard-to-reach and difficult for the organization of the construction site sections of the route. The experience of successful application of the developed technology "Saturn" on the railroad during the repair and reconstruction of long-maintained culverts of stone and concrete pipes under the conditions of a constant intensive watercourse and at water disposal facilities during repair of deep tunnels without their decommissioning is described.
\end{abstract}

\section{Degree of wear and the particularities of operation of the tunnel sewage collectors}

Nowadays the total network of the tunnel sewage collectors in large cities is up to 600 $\mathrm{km}$, and in St. Petersburg is about $270 \mathrm{~km}$. The system of sewage tunnel collectors represents pipelines of the diameter of $1.5-4.7 \mathrm{~m}$ excavated by the mining excavation method using tunneling machines at the depth of $6-90 \mathrm{~m}$. The major part (up to 75\%) of the tunnel sewage collectors is located in the central historical part of the city in very difficult geotechnical and hydrogeological conditions in terms of construction and it does not have any doublers.

\footnotetext{
* Corresponding author: perminov-n@mail.ru
} 
Within the central part of the city the strong crystal deposits are encountered at the depth of 120-220 m. Down to the depth of 30-120 m soil strata are represented by silty saturated sands of medium density - $\mathrm{E}=7-11 \mathrm{MPa}, \mathrm{C}=0 \mathrm{MPa}, \varphi=27-30^{\circ}$; plastic silty clayey sands $\mathrm{E}=3-5 \mathrm{MPa}, \mathrm{C}=0,01-0,02 \mathrm{MPa}, \varphi=12-17^{\circ}$; stratified liquid-plastic silty sandy clays $\mathrm{E}=5-8 \mathrm{MPa}, \mathrm{C}=0,015-0,025 \mathrm{MPa}, \varphi=10-16^{\circ}$; silty sandy clays with semi-solid gravel, pebbles - $\mathrm{E}=12-15 \mathrm{MPa}, \mathrm{C}=0,016-0,028 \mathrm{MPa}, \varphi=24-28^{\circ}$. The whole soil bulk is unstable to technogenic influences. Only in the southern part of the city there is a roof of dislocated Due to the scouring of pre-quaternary deposits by paleo-rivers, the bulk of quaternary deposits is characterized by a large weir of absolute elevations [1]. Non-symmetric strata of soils of different strengths are characterized by sharp slopes reaching $50 \%$ and more. This factor is especially detrimental for long-operated tunnel sewage collectors in the light of increasing anthropogenic impacts, firstly the vibro-dynamic ones [2].

\section{Analysis of the influence of anthropogenic factors on reliability of the long-operated sewage tunnels}

There have been analyzed the archive data of technical inspections of the tunnel collectors belonging to the "Vodokanal-SPb" by the maintenance service. In the period from the late 1970s to nowadays the authors have conducted the tool inspections of the technical state of the tunnels (the total length of about $15 \mathrm{~km}$ ) located in the historical city center (the depth of $12-15 \mathrm{~m}$ ) and beyond it, within the approaches to three main sewage pumping stations collecting all sewage outflows of the city, embedded at the depths of 53-71m (figure1).

a

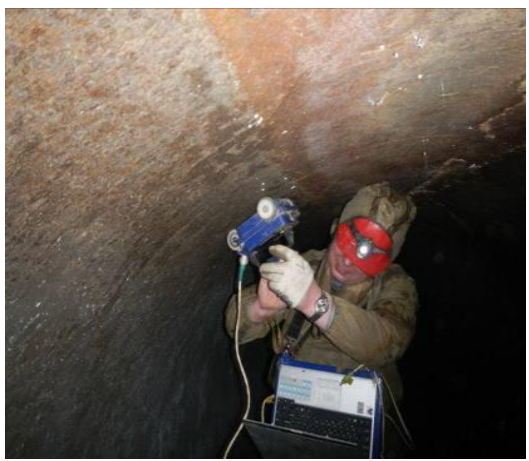

b

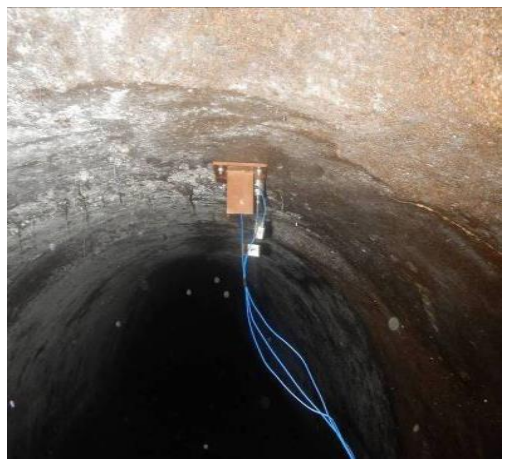

Fig. 1. Tests of the structures in the operating tunnel sewage collector: a) oscillation measurements using the ICP accelometers; b) scanning integrity of the structures of the tunnel using a georadar OKO-2.

Uniqueness of the data on observations of the state of the tunnels is that the technical inspection of the structures has been conducted during the long period since the late 1970s to nowadays (the end of 2016). During this period the same parts of collectors have been inspected several times. As a rule, each inspection was followed up by the tunnel state monitoring performed for several years. Therefore, there has appeared a possibility to track the dynamics of defects development.

The observation period was divided into three sub-periods:

a) the $1970-80 \mathrm{~s}$; b) the $1980-2000 \mathrm{~s}$; c) $2000-2016$. The identified defects which are more typical and influencing the exploitation reliability and bearing capacity of the tunnel were divided into 7 groups: d1- shrinkage cracks in the concrete liner; d2- gas corrosion features; d3- dripping leakages; d4- force cracks in the arch and along the lateral surface of 
the tunnel; d5- concrete biological corrosion features; d6- reinforcement corrosion, conduit dusting; d7- the presence of heading leakages.

The Figure 2 shows the dynamics and structure of defect manifestation during the operation period of the tunnel sewage collectors from the late 1970s to 2016.
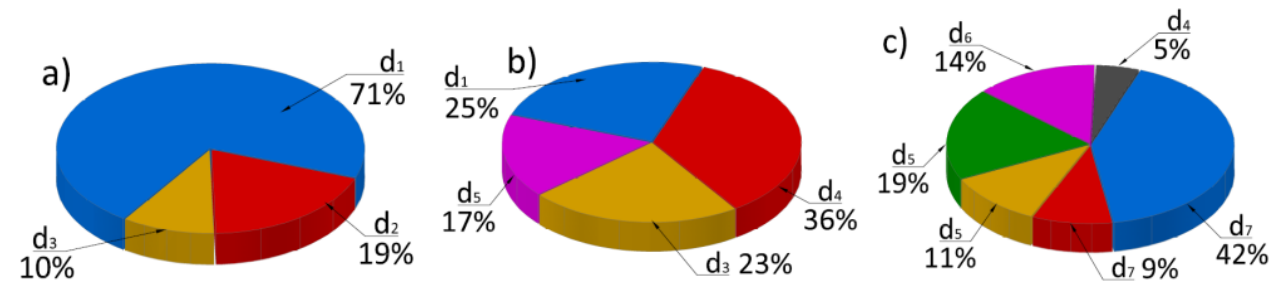

Fig. 2. The dynamics and structure of defect manifestation in a long-term operation period of tunnel sewage collectors: a) 1970-80s; b) 1980-2100s; c) 2000-2016. Classification of defects: d1-d7 primary defects caused by shrinkage cracks and manifestation of gas corrosion features before development of force cracks and occurring heading leakages (see description in the text).

The nature of the defects prevailing in the first 15-20 years of the tunnel exploitation and their influence on the bearing capacity and exploitation reliability can be considered as negligible; their technical state can be regarded as serviceable according to the existing Russian State Standards and Construction Codes.

The subsequent 20 years of the tunnel operation are characterized by manifestation of force cracks and considerable increase of the defects in concrete due to its gas and biological corrosion. However, their technical state was described as partially serviceable.

The analysis of the defects appeared in the period of 2000-2016 is of particular interest. It is noteworthy that in this period the amount of the defects influencing the tunnel bearing capacity has increased: almost $40 \%$ growth in the number of force cracks in the arch and along the lateral surface of the tunnel; the features of reinforcement corrosion and dusting of the conduit; the presence of heading leakages in the tunnel body; the increase in the proportion of the defects associated with biological and gas corrosion. The technical state of the tunnel structure is characterized as partially capable. The tunnel sewage collectors require monitoring of their technical state, taking actions on reconstruction of the bearing capacity and exploitation reliability of the structure. The comprehensive long-term technical inspections of the tunnel sewage collectors allow conducting a retrospective analysis and identifying factors, which condition manifestation and development of the defects. The factors can be divided into internal and external ones according to the nature of their influence.

The nature of the internal factors is explained by the processes linked to transportation of sewage outflows $[3,4]$.

The external factors are characterized by the complex interaction of the tunnel structure and the embedding soil bulk, which form a natural-technical system under the influence of the anthropogenic factors.

The evaluation of this interaction and definition of the area of the ultimate acceptable values of mutual influence of the natural-technical system elements is a task of geotechnical predictions. Other papers of the author is dedicated to the issues of optimum management of the natural-technical system elements [5,6].

In the framework of the given inspection we have a task of geotechnical support of the safe level of external anthropogenic impacts on the tunnel structure with account of its residual bearing capacity. 


\section{Geotechnical measures of protection of the tunnel sewage collectors}

Geotechnical and structural measures to ensure reliability and safety of the long-operated tunnel sewage collectors should be selected basing on comparison of competing options, but the main requirement they should meet is a possibility of preventive use substantiated by geotechnical and structural calculations. The Table 1 presents examples of some geotechnical measures successfully taken in the projects of protection of the tunnel sewage collectors in St. Petersburg in 1998-2016.

Table 1. Geotechnical measures of protection of the tunnel sewage collectors.

\begin{tabular}{|c|c|c|}
\hline $\begin{array}{l}\text { The nature of technogenic } \\
\text { impacts }\end{array}$ & $\begin{array}{c}\text { Geotechnical and structural } \\
\text { measures }\end{array}$ & The object for protection \\
\hline $\begin{array}{l}\text { Supernormative static and } \\
\text { dynamic influences on the } \\
\text { brickwork arch of the } \\
\text { collector }\end{array}$ & $\begin{array}{l}\text { Construction of an unloading } \\
\text { screen and reinforcement of } \\
\text { the structures; monitoring. }\end{array}$ & $\begin{array}{l}\text { The brickwork sewage } \\
\text { collector XVIII century } \\
\text { under Konnogvardeysky } \\
\text { boulevard }\end{array}$ \\
\hline $\begin{array}{l}\text { The increase in static load } \\
\text { applied to the tunnel sewage } \\
\text { collector due to the weight of } \\
\text { the building being constructed } \\
\text { above it }\end{array}$ & $\begin{array}{l}\text { Construction of an unloading } \\
\text { bridge with load transfer to } \\
\text { the soils below the tunnel } \\
\text { bottom, monitoring. }\end{array}$ & $\begin{array}{l}\text { The sewage collector in } \\
\text { Nalichnaya street }\end{array}$ \\
\hline $\begin{array}{l}\text { Unloading of a soil bulk } \\
\text { during the construction of the } \\
\text { deep transport tunnel above } \\
\text { the tunnel sewage collector }\end{array}$ & $\begin{array}{l}\text { Construction of a protective } \\
\text { screen of reinforced soil to } \\
\text { prevent the uplift of the pit } \\
\text { bottom, monitoring. }\end{array}$ & $\begin{array}{l}\text { The transport tunnel above } \\
\text { the tunnel sewage collector } \\
\text { along the Obvodny Canal } \\
\text { and the bridge of Alexander } \\
\text { Nevsky }\end{array}$ \\
\hline $\begin{array}{l}\text { Prevention of horizontal } \\
\text { displacement of the tunnel } \\
\text { sewage collector at unilateral } \\
\text { unloading of a soil bulk } \\
\text { during reconstruction of the } \\
\text { embankment. }\end{array}$ & $\begin{array}{l}\text { Construction of a } \\
\text { geotechnical barrier, } \\
\text { monitoring. }\end{array}$ & $\begin{array}{l}\text { The tunnel sewage collector } \\
\text { along the highway in the } \\
\text { embankment of the } \\
\text { Fontanka River }\end{array}$ \\
\hline $\begin{array}{l}\text { Expansion of an area of } \\
\text { ultimate acceptable } \\
\text { displacements of the tunnel } \\
\text { sewage collector at unilateral } \\
\text { unloading of a soil bulk } \\
\text { during reconstruction of the } \\
\text { embankment. }\end{array}$ & $\begin{array}{l}\text { Structural reinforcement and } \\
\text { sanation of the tunnel sewage } \\
\text { collector using the spiral- } \\
\text { coiling method in order to } \\
\text { increase the ultimate } \\
\text { acceptable tunnel } \\
\text { displacements, monitoring. }\end{array}$ & $\begin{array}{l}\text { The tunnel sewage collector } \\
\text { along the embankment of } \\
\text { the Kryukov Canal and the } \\
\text { Moyka River }\end{array}$ \\
\hline $\begin{array}{l}\text { The increase in static load } \\
\text { applied to the tunnel sewage } \\
\text { collector due to the impact of } \\
\text { heavy road transport and } \\
\text { trams. }\end{array}$ & $\begin{array}{l}\text { Structural reinforcement and } \\
\text { sanation of the tunnel sewage } \\
\text { collector using the coiling } \\
\text { method in order to restore the } \\
\text { bearing capacity of the tunnel } \\
\text { up to the design level, } \\
\text { monitoring. }\end{array}$ & $\begin{array}{l}\text { The } 840-\text { m-long tunnel } \\
\text { sewage collector in } \\
\text { Tovarischesky prospect }\end{array}$ \\
\hline
\end{tabular}

The calculation substantiation of the geotechnical protection measures was made according to the algorithm: collection of loads and impacts, definition of the physicalmechanical properties of soil and tunnel materials; creation of a geo-mechanical calculation model and calculation of displacements using the software Plaxis3DTunnel; creation of a calculation model using the software Robol; selection of the parameters of tunnel reinforcement. The calculation example is shown in the figure 3. 


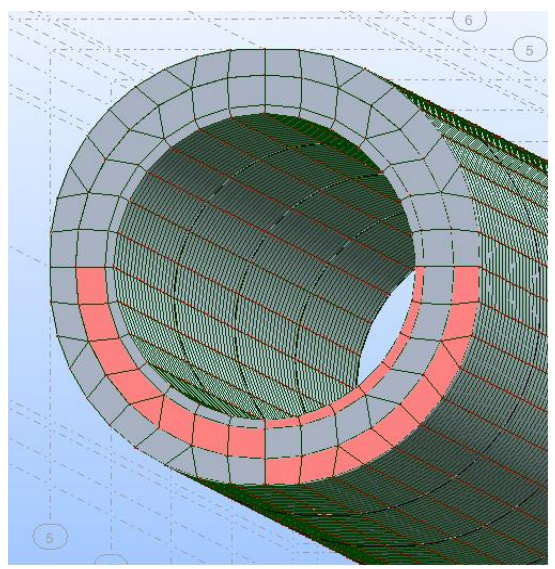

$\mathrm{b}$

1

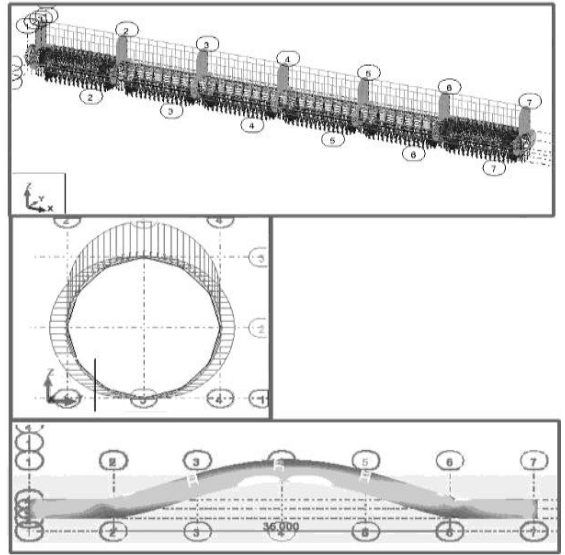

Fig. 3. The fragments of the calculation scheme - (a) simulation of the ultimate acceptable displacement of the collector - (b): 1- the collector tubings; 2 - the concrete liner; 3-the layer of reinforcement and sanation using the coiling method.

\section{Application geotechnical measures during repairing of the tunnel sewage collectors in conditions of sewage outflows transportation}

The tunnel collector in Tovarischecky prospect with the intervals $359 \mathrm{~m}$ and $485 \mathrm{~m}$ diameters $\mathrm{D}=2.5 \mathrm{~m}$ and $\mathrm{D}=1.5 \mathrm{~m}$ at the depth of $1274 \mathrm{~m}$ has been operating for more than 40 years. According to the inspection results the wear degree was more than $79 \%$, the subsidence at the crossroads reached $25 \mathrm{~mm}$. It was necessary to ensure protection of the tunnel sewage collector against the enhanced external static and dynamic transport loads and impacts. According to the georadar scanning there was identified overall peeling of the concrete liner from the tubing lining with occurrence of heading leakages (Figure 4).

a

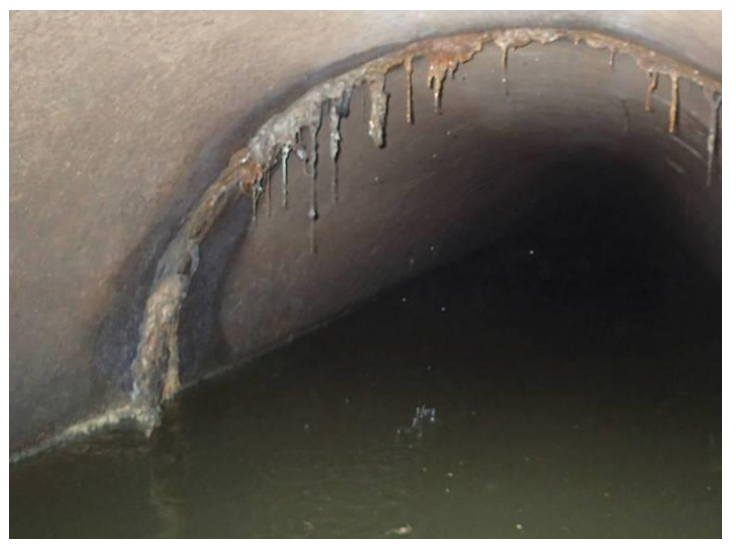

b

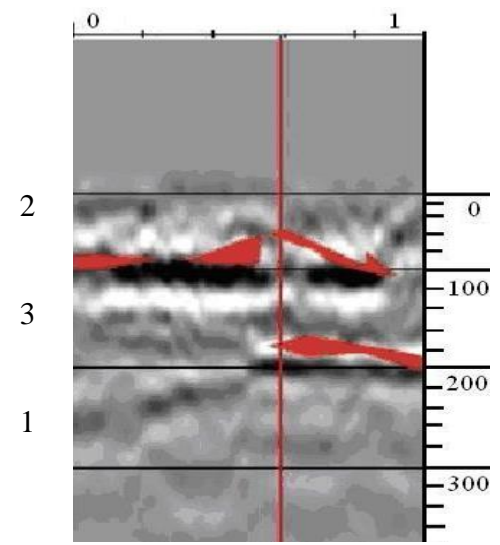

Fig. 4. The defect of peeling the structures: a) heading leakage features; b) a fragment of the radargram with the features of peeling the tunnel structures - 1-tubing lining; 2 - RC liner; 3 - a heading water layer.

The calculation sequence followed the algorithm above mentioned in section 4 of the paper, the calculation fragments are shown in (Figure 2), the ultimate acceptable 
displacements before the protection measures and after them are shown in the graph (Figure 5): $1-\mathrm{D}=1.5 \mathrm{~m}, 3-\mathrm{D}=2.5 \mathrm{~m}$ - tubing lining with defects of the concrete liner; $2-\mathrm{D}=1.5 \mathrm{~m}$, 4- $\mathrm{D}=2.5 \mathrm{~m}$ - tubing lining with reconstruction of the concrete liner and refractory lining reinforcement of the structure.

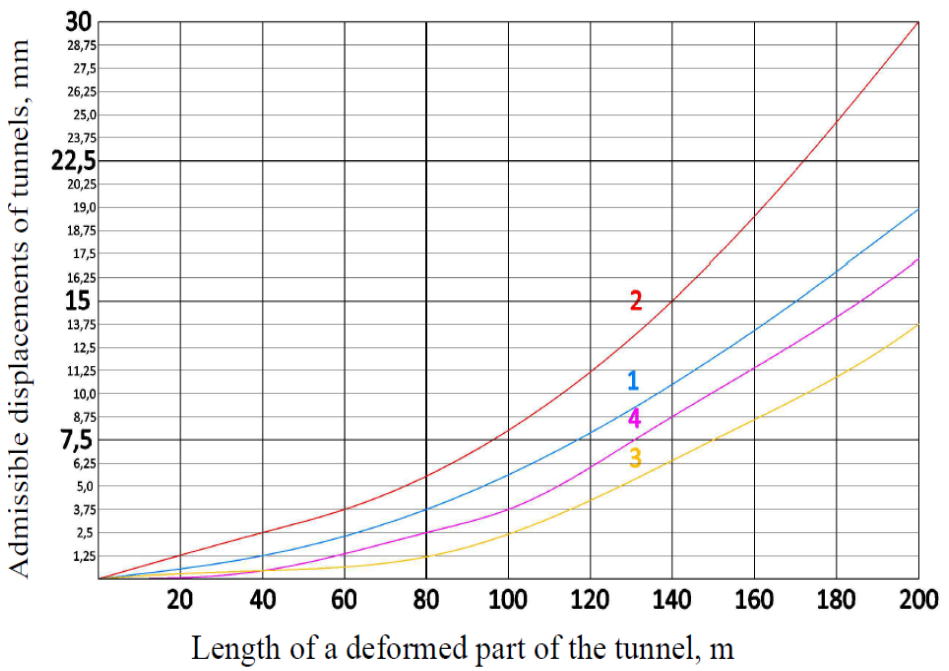

Fig. 5. The ultimate acceptable displacements of the sewage tunnels $D=1.5$ and $D=2.5$ before (1.3) and after (2.4) reinforcement of the structure using coiling technology.

A special requirement for the protection measures was the use of such a method which allowed repairing in conditions of constant transportation of sewage outflows.

a

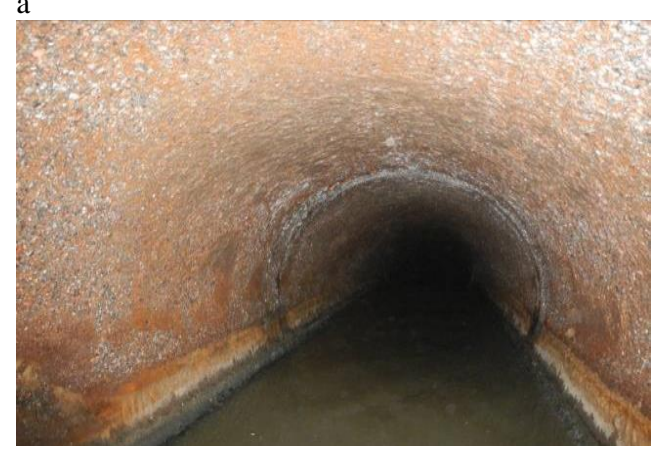

b

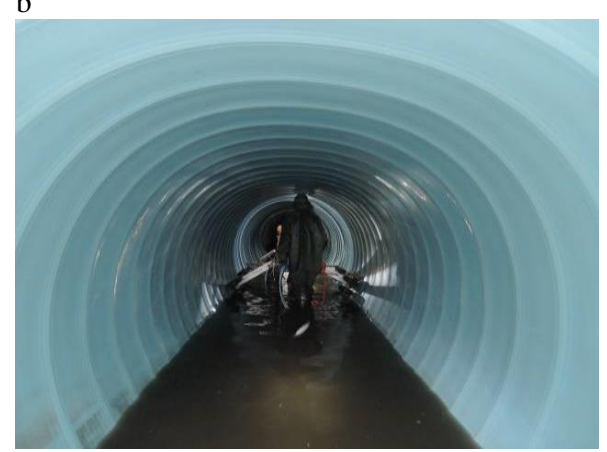

Fig. 6. The state of the tunnel sewage collector: - a) before the repair and b) after the reinforcement of the structure and its sanation using the coiling method.

The sanation technology by coiling was applied for repairing and restoring bearing capacity of the tunnel. The scope of working operations included: cleaning the tunnel and preparing the surface; structural gluing of the concrete liner and the tubing lining by injection of SikaDur; reinforcing the arch surface by structural reinforcement with SikaWrap carbon fiber; coating the tunnel surface with PVC coiling profile; injecting polymer-cement mortar $($ Pcomp. $=65 \mathrm{MPa})$ into the intertubular space for structural gluing of the PVC lining with the tunnel structure. The operation fragments are shown in (Figure 6). According to the conducted monitoring it was found out that vibro-dynamic tests of the tunnel before and after the repair demonstrated changes of the period of the collector's own 
oscillations from $0.54 \mathrm{sec}$. to $0.19 \mathrm{sec}$. i.e. by $58 \%$, the amplitude of its own oscillations decreased from $A=300$ micron to $A=15$ micron, i.e. almost by 2 degrees of order. It shows provision of the integrity of the structure and joint operation of its layers (Figure 7). After repairing the guaranteed period of reliable work of the tunnel sewage collector is minimum 50 years.

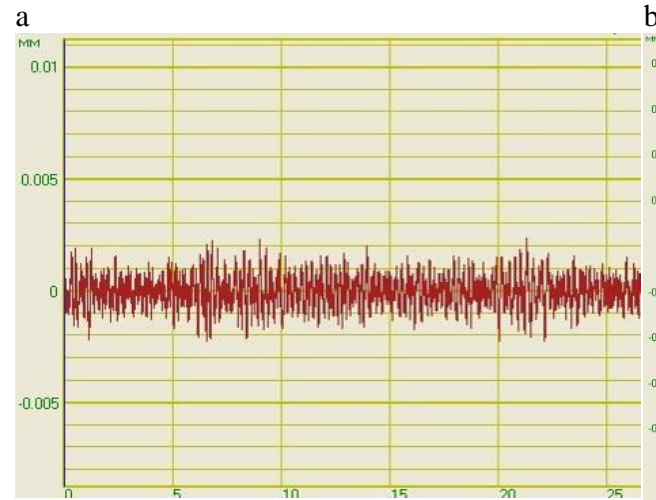

b

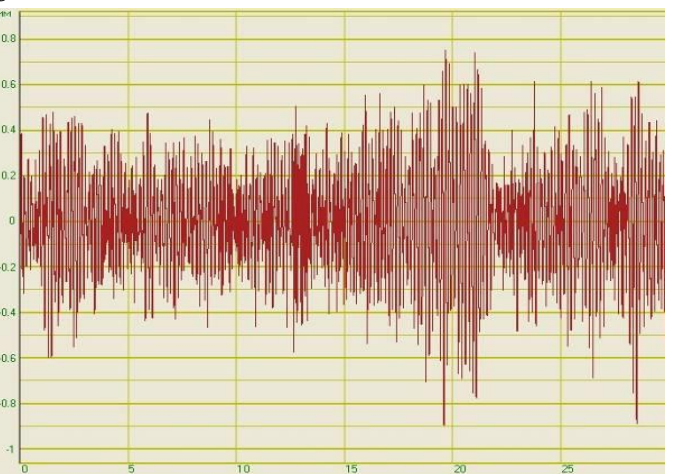

Fig. 7. The results of the measurement of the oscillations of the tunnel structures at applying the exterior vibro-dynamic transport load: a) the oscillogram of the fluctuation process of the tunnel structures with the peeling defects $A=300-800$ micron and) the same after reinforcement with "the structural gluing" and sanation using the coiling method $A=15-20$ micron.

\section{Conclusions}

Due to long operation, the tunnel sewage collectors in Russia have a wear of $55 \div 66 \%$. Complicated soil conditions in St. Petersburg have led to the wear of the tunnel sewage collectors up to $83 \%$ with the fast dynamic of development $1.5 \div 2 \%$ because of the action of different technogenic factors. The proposed geotechnical methods of protection of the tunnel sewage collectors including the methods of structural reinforcement and sanation in conditions of transporting sewage outflows accompanied by the monitoring system provide enhancement of the bearing capacity of the structure of the tunnel sewage collectors and their exploitation reliability.

\section{References}

1. R.E. Dashko, Urban development and geotechnical engineering 1, 1-47 (2011)

2. N.A. Perminov, Geotechnical aspects of security for long-operated underground collectors in conditions of soft soils and increasing technogenic influences, Proceedings of the 19th International Conference on Soil Mechanics and Geotechnical Engineering, 1757-1760 (2017)

3. G.A. Pankova, M.N. Klementiev, Water supply and sanitary equipment 3, 55-61 (2015)

4. V.M. Vasiliev, G.A. Pankova, Yu.V. Stolbikhin, Water supply and sanitary equipment 9, 55-61 (2013)

5. N.A. Perminov, Complete geotechnical and monitoring services for the construction of the underground structure in a megapolis, Proceedings of the International Geotechnical Conference, 361-366 (2004)

6. N.A. Perminov, Geotechnics of Roads and Railways, 1195-1201 (2014) 